\title{
Optimization of butanol production from corn straw hydrolysate by Clostridium acetobutylicum using response surface method
}

\author{
LIN YouSheng ${ }^{1,2}$, WANG Jing ${ }^{2}$, WANG XuMing ${ }^{1} \&$ SUN XiaoHong ${ }^{1^{*}}$ \\ ${ }^{1}$ Beijing Agro-Biotechnology Research Center, Beijing Academy of Agriculture and Forestry Sciences, Beijing 100097, China; \\ ${ }^{2}$ School of Environmental and Biological Science and Technology, Dalian University of Technology, Dalian 116024, China
}

Received January 6, 2010; accepted August 16, 2010

\begin{abstract}
Butanol is a new kind of very potential biofuels. Enzymatic hydrolysis of corn stalk was utilized in this study to produce butanol by Clostridium acetobutylicum CICC 8008. Plackett-Burman (P-B) design and Central Composite Design (CCD) were adopted to screen crucial factors during fermentation as well as the optimization of experimental conditions. The result demonstrated that among the seven factors, namely, Yeast extract, $\left(\mathrm{NH}_{4}\right)_{2} \mathrm{SO}_{4}, \mathrm{KH}_{2} \mathrm{PO}_{4}, \mathrm{MgSO}_{4}, \mathrm{FeSO}_{4}, \mathrm{CuSO}_{4}$ and $\mathrm{CaCO}_{3}$, only $\mathrm{CaCO}$ was selected as the most critical factor. The optimization experiment results for $\mathrm{CaCO}_{3}$ usage, temperature and reaction time by $\mathrm{CCD}$ were determined to be $5.04 \mathrm{~g} / \mathrm{L}, 35^{\circ} \mathrm{C}$ and $70 \mathrm{~h}$, respectively. A corresponding mathematical model was established to predict the fermentation experiment and maximum butanol yield of $6.57 \mathrm{~g} / \mathrm{L}$ was acquired. The result of verification experiment under the optimum conditions showed that $6.20 \mathrm{~g} / \mathrm{L}$ was the maximum butanol yield. This demonstrated that statistical method was a powerful tool for the optimization of butanol production from enzymatic hydrolysis of corn stalk.
\end{abstract}

enzymatic hydrolysis, butanol fermentation, Plackett-Burman design, response surface method

Citation: $\quad$ Lin Y S, Wang J, Wang X M, et al. Optimization of butanol production from corn straw hydrolysate by Clostridium acetobutylicum using response surface method. Chinese Sci Bull, 2011, 56: 1422-1428, doi: 10.1007/s11434-010-4186-0

Environmental pollution due to the use of fossil fuels as well as their shortfall makes it necessary to find alternative energy source that are environmentally friendly and renewable. Researches have been intensified towards the production of alternative fuels such as butanol by fermentation [1]. Because butanol is not only an excellent feedstock chemical (in the plastic industry), a food-grade extractant (in the food and flavor industry), but also a replacement for gasoline as a fuel, a superior fuel to ethanol for higher energy content and safety [2-5]. Butnaol fermentation by the anaerobic bacterium Clostridium. acetobutylicum or $C$. beijerinckii is one of the oldest known industrial fermentations. It was ranked second only to ethanol fermentation by yeast in its scale of production, and is one of the largest biotechnological processes ever known [6-8]. Since the substrate cost affects the price of butanol production by fermentation, the use of

*Corresponding author (email: sunxiaohong19675@yahoo.com.cn) abundant inexpensive renewable resources as feedstock for fementation such as agricultural residues, energy crops and wastes is a promising way to bring down the cost $[9,10]$. Unfortunately, C. acetobutylicum is not able to efficiently hydrolyze fiber-rich agricultural residues. For this reason, agricultural biomass must be pretreated and hydrolyzed to simple sugars using economical methods.

The agricultural residues including corn straw, wheat straw and wood are composed primarily of polysaccharides that contain six and five carbon sugars. Prior to using these substrates, agricultural residues should be hydrolyzed using a combination of alkali pretreatment and cellulase [11-13]. In order to make better use of enzyme hydrolyzate, the optimization of fermentation conditions, particularly nutritional and environmental parameters which play importance roles that influence cell growth, solvent and acid production, is very necessary $[14,15]$. The statistical methods are believed to be effective and powerful approaches for 
screening key factors rapidly from a multivariable system to optimize fermentation conditions and therefore have been extensively used recently [16].

In the current study, we adopted corn straw as a potential substrate for butanol fermentation employing C. acetobutylicum. The effects of nutrition components were evaluated using Plackett-Burman design, and the optimum fermentation conditions for butanol production were optimized by Central Composite Design (CCD).

\section{Materials and methods}

\subsection{Strain and inoculation preparation}

C. acetobutylicum CICC 8008 was obtained from China Center of Industrial Culture Collection which was stored at $4^{\circ} \mathrm{C}$. Spores of C. Clostridium were heat shocked at $100^{\circ} \mathrm{C}$ for $1.5 \mathrm{~min}$ followed by transferring to glucose-based fresh medium.

The basal medium contained (g/L): glucose, 10; tryptone, 5; yeast extract, 5; soya peptone, 5; $\mathrm{K}_{2} \mathrm{HPO}_{4}$, 0.5; $\mathrm{MgSO}_{4} \cdot 7 \mathrm{H}_{2} \mathrm{O}, 0.2 ; \mathrm{FeSO}_{4} \cdot 7 \mathrm{H}_{2} \mathrm{O}, 0.01 ;$ L-cysteine, 0.5 . The mixture was autoclaved at $121^{\circ} \mathrm{C}$ for $15 \mathrm{~min}$ followed by cooling to room temperature. The heat-shocked spores were incubated for $14-16 \mathrm{~h}$ at $37^{\circ} \mathrm{C}$ prior to inoculation.

\subsection{Corn straw pretreatment and hydrolysis}

Corn straw, obtained from a local farm, was ground to fine particles ( $1 \mathrm{~mm}$ sieve screen) using a hammer mill. Corn straw contained $30 \%$ cellulose, $27 \%$ hemicellulose, and relatively low lignin $(<20 \%)$. One hundred gram of corn straw powder was suspended in $1 \mathrm{~L}$ diluted sodium hydroxide (30 $\mathrm{g}$ sodium hydroxide in $1 \mathrm{~L}$ distilled water) in a breaker followed by immersing at room temperature for 24 h. Subsequently, the mixture was adjusted $\mathrm{pH}$ to 7.0 with 10 $\mathrm{M} \mathrm{HCl}$ followed by drying in the oven. After this, $1 \mathrm{~kg}$ of the $\mathrm{NaOH}$-pretreated corn straw was added to $10 \mathrm{~L}$ crude enzyme solutions (cellulase; supplier-Aoboxing Biotech Corporation, China) with 4.5 FPU/g (straw) and then adjust $\mathrm{pH}$ to 5.0 with $1 \mathrm{M} \mathrm{HCl}$. Finally, the mixture was incubated at $50^{\circ} \mathrm{C}$ for $72 \mathrm{~h}$ with agitation at $100 \mathrm{r} / \mathrm{min}$. Following this, the mixture was filtered by eight layers of gauze and centrifuged at $8000 \mathrm{r} / \mathrm{min}$ for $10 \mathrm{~min}$. The supernatant was selected and then the clear liquid solution was stored in a screw capped bottle at $-20^{\circ} \mathrm{C}$ for fermentation studies to be conducted later. The hydrolysate contained approximately $42-44 \mathrm{~g} / \mathrm{L}$ total sugars.

\subsection{Batch fermentation}

Anaerobic batch fermentations were carried out in $100 \mathrm{~mL}$ serum bottles containing $50 \mathrm{~mL}$ medium. The reactor contained $50 \mathrm{~mL}$ of hydrolysate and $2.5 \mathrm{~mL}$ of the prepared bacteria to make a final media volume of $52.5 \mathrm{~mL}$. An- aerobiosis was ensured by flushing oxygen-free nitrogen gas through the medium with the Hungate Anaerobic Culture Technique [17]. The fermentations were conducted at $\mathrm{pH} 7$ and $37^{\circ} \mathrm{C}$.

\subsection{Analytical methods}

Fermentation products were analyzed by gas chromatography (6890N; Agilent Technologies) using a $30 \mathrm{~m} \times 0.25 \mathrm{~mm}$ $\times 0.25 \mu \mathrm{m}$ capillary column packed with FFAP(free fatty acid phase; polyethylene-glycol TPA-modified; Hewlettpackard) and a flame ionization detector. The initial and final temperatures were $60^{\circ} \mathrm{C}$ and $210^{\circ} \mathrm{C}$, respectively. The temperatures of the injector and detector temperatures were $220^{\circ} \mathrm{C}$ and $240^{\circ} \mathrm{C}$. Hydrogen was used as the carrier gas at flow rate of $7.8 \mathrm{~mL} / \mathrm{min}$. Samples $(0.2 \mu \mathrm{L})$ were injected in the GC and isobutanol was used as an internal standard [18].

\subsection{Experiment design and statistical analysis}

(i) Plackett-Burman design. The Plackett-Burman (P-B) design, an effective technique for medium-component optimization, was used to select factors that significantly influenced butanol production. This experimental design was a two factorial design, which identified the critical physico-chemical parameters required for elevated butanol production by screening $n$ variables in $n+1$ experiments $[19,20]$. The technique is based on the first-order polynomial model:

$$
Y=\beta_{0}+\sum \beta_{i} X_{i}
$$

where $Y$ is the respone(butanol production), $\beta_{0}$ is the model intercept and $\beta_{i}$ is the linear coefficient and $X_{i}$ is the level of the independent variable. An 8-run of P-B design matrix generated by the statistical software package STATISTICA 6.0 (StatSoft Inc., USA) was multiplied (Table 1 run 8), and then used to investigate the effects of supplemental nutrients on the butanol fermentation by $C$. acetobutylicum. The high levels of the nutrients yeast extract(A), $\left(\mathrm{NH}_{4}\right)_{2} \mathrm{SO}_{4}(\mathrm{~B})$, $\mathrm{KH}_{2} \mathrm{PO}_{4}(\mathrm{C}), \mathrm{MgSO}_{4} \cdot 7 \mathrm{H}_{2} \mathrm{O}(\mathrm{D}), \mathrm{FeSO}_{4} \cdot 7 \mathrm{H}_{2} \mathrm{O}(\mathrm{E}), \mathrm{CuSO}_{4} \cdot$ $5 \mathrm{H}_{2} \mathrm{O}(\mathrm{F}), \mathrm{CaCO}_{3}(\mathrm{G})$ were $0.1 \%, 0.1 \%, 0.05 \%, 0.05 \%$, $0.01 \%, 0.01 \%, 0.4 \%(w / v)$, respectively. The seven nutrients were examined to investigate the key ingredients significantly affecting the production of butanol. The experimental design for the screening of the variables is showed in Table 1. All the variables were denoted as numerical factors and investigated at two widely spaced intervals designated as -1 (low level) and +1 (high level). The effects of individual parameters on butanol production were calculated by the following equation:

$$
E_{x}=\frac{\sum Y(+1)-\sum Y(-1)}{n / 2},
$$


Table 1 Plackett-Burman experimental design for the screening of significant process variables affecting butanol production

\begin{tabular}{ccccccccc}
\hline Code & Yeast extract $(\mathrm{g} / \mathrm{L})$ & $(\mathrm{NH} 4)_{2} \mathrm{SO}_{4}(\mathrm{~g} / \mathrm{L})$ & $\mathrm{KH}_{2} \mathrm{PO}_{4}(\mathrm{~g} / \mathrm{L})$ & $\mathrm{MgSO}_{4}(\mathrm{~g} / \mathrm{L})$ & $\mathrm{FeSO}_{4}(\mathrm{~g} / \mathrm{L})$ & $\mathrm{CuSO}_{4}(\mathrm{~g} / \mathrm{L})$ & $\mathrm{CaCO}(\mathrm{g} / \mathrm{L})$ & $\mathrm{Butanol}(\mathrm{g} / \mathrm{L})$ \\
\hline 1 & 0 & 0 & 0 & 0.2 & 0.05 & 0.05 & 2 & 2.28 \\
2 & 1 & 0 & 0 & 0 & 0 & 0.05 & 8 & 6.67 \\
3 & 0 & 1 & 0 & 0 & 0.05 & 0 & 8 & 6.41 \\
4 & 1 & 1 & 0 & 0.2 & 0 & 0 & 2 & 1.34 \\
5 & 0 & 0 & 0.5 & 0.2 & 0 & 0 & 8 & 7.03 \\
6 & 1 & 0 & 0.5 & 0 & 0.05 & 0 & 2 & 1.85 \\
7 & 0 & 1 & 0.5 & 0 & 0 & 0.05 & 2 & 3.51 \\
8 & 1 & 1 & 0.5 & 0.2 & 0.05 & 0.05 & 8 & 6.70 \\
\hline
\end{tabular}

where $E$ is the effect of parameter under the experiment conditions, and $\sum Y(+1), \sum Y(-1)$ are the sum of responses (butanol production) of trials at which the parameter was at its higher and lower levels, respectively, and $n$ is the total number of trials.

(ii) Central composite design. The response surface methodology was used to optimize the screened variables for enhanced butanol production based on Central Composite Design (CCD), which is helpful to investigate linear, quadratic, and cross-product effects of the three reaction condition variables on the butanol production [21-23]. The experimental data were analyzed by RSM using the following second-order polynomial equation:

$$
Y=\beta_{0}+\sum_{i=1}^{n} \beta_{i} X_{i}+\sum_{i=1}^{n} \beta_{i i} X_{i}^{2}+\sum \sum_{i<j=1}^{n} \beta_{i j} X_{i} X_{j},
$$

where $Y$ is the response (butanol production, $\mathrm{g} / \mathrm{L}$ ); $X_{i}$ and $X_{j}$ are the coded independent variables and $\beta_{0}, \beta_{i}, \beta_{i i}, \beta_{i j}$ are intercept, linear, quadratic, and interaction constant coefficients, respectively. Subsequently, The maximum response variable and the corresponding variables were estimated from eq. (3).

STATISTICA 6.0 was used for regression analysis and analysis of variance (ANOVA). Response surfaces and contour plots were developed using the fitted quadratic polynomial equation obtained from regression analysis, corresponding to the stationary point and the changing of the other two variables.

\section{Results and discussion}

\subsection{Effect of supplemental nutrients in butanol pro- duction}

In order to understand the role of the nutrients condition of butanol fermentation, the relative significance of seven nutrients, including yeast extract, $\left(\mathrm{NH}_{4}\right)_{2} \mathrm{SO}_{4}, \mathrm{KH}_{2} \mathrm{PO}_{4}$, $\mathrm{MgSO}_{4} \cdot 7 \mathrm{H}_{2} \mathrm{O}, \mathrm{FeSO}_{4} \cdot 7 \mathrm{H}_{2} \mathrm{O}, \mathrm{CuSO}_{4} \cdot 5 \mathrm{H}_{2} \mathrm{O}$, and $\mathrm{CaCO}_{3}$ were investigated by $\mathrm{P}-\mathrm{B}$ design, As seen in Table 2, the main effect of each variable upon butanol production was estimated as the difference between both averages of measurement made at the high level $(+1)$ and the low level $(-1)$ of the factors. After the estimation of the factors regression coefficients, the determination of the significant factors affecting the dependent variables of interest (response) was following by performing analysis of variance (ANOVA) (Table 2). $F$ statistics and $P$ values were not available since all the available degrees of freedom were used for the calculation of the factors main effects [24]. A common way to avoid this difficulty is to pool some less important factors into error. In the analysis process, $(\mathrm{NH})_{4} \mathrm{SO}_{4}$ was used as the less important factor. According to $S S, P$ and $E$, the significance of nutrients could be ranked as $\mathrm{CaCO}_{3}>$ Yeast extract $>\mathrm{CuSO}_{4} \cdot 5 \mathrm{H}_{2} \mathrm{O}$ $>\mathrm{KH}_{2} \mathrm{PO}_{4}>\mathrm{FeSO}_{4} \cdot 7 \mathrm{H}_{2} \mathrm{O}>\mathrm{MgSO}_{4} \cdot 7 \mathrm{H}_{2} \mathrm{O}>\left(\mathrm{NH}_{4}\right)_{2} \mathrm{SO}_{4}$. From the data analysis, Yeast extract, $\mathrm{KH}_{2} \mathrm{PO}_{4}, \mathrm{CuSO}_{4} \cdot 5 \mathrm{H}_{2} \mathrm{O}$, $\mathrm{CaCO}_{3}$ displayed a positive effect on butanol production. The variables with confidence levels greater than $95 \%$ were considered as influencing butanol production significantly. $\mathrm{CaCO}_{3}$ was significant at above $99.9 \%$ confidence levels for butanol production.

Yeast extract, $\mathrm{MgSO}_{4} \cdot 7 \mathrm{H}_{2} \mathrm{O}$ and $\mathrm{FeSO}_{4} \cdot 7 \mathrm{H}_{2} \mathrm{O}$ were found insignificant with negative coefficients for butanol production. Whereas, $\mathrm{KH}_{2} \mathrm{PO}_{4}$ and $\mathrm{CuSO}_{4} \cdot 5 \mathrm{H}_{2} \mathrm{O}$ were found insignificant with positive coefficients for butanol production, which would not be included in the next optimization experiments. Thus $\mathrm{CaCO}_{3}$ was only chosen for further optimization by CCD. This result suggested that the effect of $\mathrm{CaCO}_{3}$ would be due to its buffering capacity of the medium. The influence of $\mathrm{pH}$ has been recognized as a key factor in determining the outcome of butanol fermentation, and many of the early reports relating to the industrial production of solvents noted that the butanol production occurred only after the $\mathrm{pH}$ of medium had decreased to around 4.5-5.0 [8]. The $\mathrm{CaCO}_{3}$ could maintain $\mathrm{pH}$ at a good level and lead to high butanol production.

\subsection{Response surface methodology}

The optimal level of the key factors (temperature, $\mathrm{CaCO}_{3}$, reaction time) and the effects of their interactions on butanol production were further explored by the Central Composite Design (CCD), which was used to develop a correlation between the condition variables to the butanol yield. The complete design matrix and butanol yield at various condition variables are listed in Table 3 . The butanol yield was in 
Table 2 Effect of nutrients in $P-B$ design on butanol production

\begin{tabular}{ccccc}
\hline Nutrient & $S S$ & $F$ & $P$ & $E^{\mathrm{a}}$ \\
\hline Yeast extract & 0.90 & 411.97 & 0.031 & -0.67 \\
$\left(\mathrm{NH}_{4}\right)_{2} \mathrm{SO}_{4}$ & 0.002 & - & - & 0.03 \\
$\mathrm{KH}_{2} \mathrm{PO}_{4}$ & 0.71 & 326.70 & 0.035 & 0.59 \\
$\mathrm{MgSO}_{4}$ & 0.15 & 66.60 & 0.078 & -0.27 \\
$\mathrm{FeSO}_{4}$ & 0.22 & 100.14 & 0.063 & -0.33 \\
$\mathrm{CuSO}_{4}$ & 0.80 & 365.15 & 0.033 & 0.63 \\
$\mathrm{CaCO}_{3}$ & 39.69 & 18139.39 & 0.005 & 4.45 \\
Error & 0.002 & & & \\
Total SS & 42.47 & & & \\
\hline
\end{tabular}

a) Effect value of nutrient.

the range from 0.3 to $6.54 \mathrm{~g} / \mathrm{L}$. By applying multiple regression analysis on the experimental data, the following second-order polynomial equation was established to explain the butanol production:

$$
\begin{aligned}
Y= & -64.70+3.41 A-0.052 A^{2}+0.18 B-0.25 B^{2}+0.21 C \\
& -0.002 C^{2}+0.06 A B+0.002 A C+0.005 B C .
\end{aligned}
$$

where $Y$ is the predicted butanol production rate; $A, B$ and $C$ are the coded values of temperature, $\mathrm{CaCO}_{3}$ and reaction time, respectively.

The analysis of variance (ANOVA) was conducted to test the significance of the fit of the second-order polynomial equation for the experimental data as shown in Table 4. ANOVA of the fitting model showed that it was highly significant $(P<0.01)$, while the lack of fit was not significant $(P>0.05)$. The coefficient of determination $\left(R^{2}\right)$ was 0.974 , which could explain $97.4 \%$ variability of the response variable. It indicated a good agreement between experimental and predicted values and implied that eq. (4) could describe the effect of temperatures, reaction time, $\mathrm{CaCO}_{3}$ concentrations on the butanol production of this study very well.

ANOVA of the fitting model also showed that the linear effect of reaction time, $\mathrm{CaCO}_{3}$ concentrations and the quadratic effect of temperatures, $\mathrm{CaCO}_{3}$ concentrations on butanol production rate were highly significant $(P<0.01)$, indicating that these terms had great impact on the butanol production rate. However, the quadratic of reaction time and the interactive effect between temperature and reaction time, $\mathrm{CaCO}_{3}$ concentrations and reaction time on butanol production were not significant $(P>0.05)$, indicating that these terms had little impact on butanol production.

Subsequently, the maximum butanol production was estimated from eq. (4) at the temperature of $35^{\circ} \mathrm{C}$, the $\mathrm{CaCO}_{3}$ concentrations of $5.043 \mathrm{~g} / \mathrm{L}$ and the reaction time of $70 \mathrm{~h}$.

The response surface plots and contour plots were shown in Figures 1-3, which depicted the interactions between two variables by keeping the other variables at zero level for butanol production. As shown in Figures 1-3, in the design

\begin{tabular}{|c|c|c|c|c|}
\hline Code & A: Temperature $\left({ }^{\circ} \mathrm{C}\right)$ & B: $\mathrm{CaCO}_{3}(\mathrm{~g} / \mathrm{L})$ & C: Reaction time (h) & Butanol yield $(\mathrm{g} / \mathrm{L})$ \\
\hline 1 & 30 & 1.36 & 48 & 1.79 \\
\hline 2 & 30 & 1.36 & 72 & 1.85 \\
\hline 3 & 30 & 5.36 & 48 & 3.17 \\
\hline 4 & 30 & 5.36 & 72 & 3.90 \\
\hline 5 & 40 & 1.36 & 48 & 1.16 \\
\hline 6 & 40 & 1.36 & 72 & 1.83 \\
\hline 7 & 40 & 5.36 & 48 & 4.98 \\
\hline 8 & 40 & 5.36 & 72 & 5.92 \\
\hline 9 & 26.6 & 3.36 & 60 & 1.29 \\
\hline 10 & 43.41 & 3.36 & 60 & 2.85 \\
\hline 11 & 35 & 0.00 & 60 & 0.30 \\
\hline 12 & 35 & 6.72 & 60 & 5.4 \\
\hline 14 & 35 & 3.36 & 80.18 & 6.54 \\
\hline 15 & 35 & 3.36 & 60 & 5.58 \\
\hline 16 & 35 & 3.36 & 60 & 5.68 \\
\hline
\end{tabular}

Table 3 Experimental design matrix and results 
Table 4 ANOVA for response surface quadratic model for butanol production ${ }^{\text {a) }}$

\begin{tabular}{cccccc}
\hline Source & $S S$ & $d f$ & Mean square & $F$-value & $P$-value \\
\hline $\mathrm{A}(\mathrm{L})$ & 2.447 & 1 & 2.447 & 9.5350 & $0.021446^{\alpha}$ \\
$\mathrm{A}(\mathrm{Q})$ & 15.487 & 1 & 15.487 & 60.3365 & 0.000240 \\
$\mathrm{~B}(\mathrm{~L})$ & 29.076 & 1 & 29.076 & 113.2782 & 0.000041 \\
$\mathrm{~B}(\mathrm{Q})$ & 9.504 & 1 & 9.504 & 37.0272 & 0.000896 \\
$\mathrm{C}(\mathrm{L})$ & 4.502 & 1 & 4.503 & 17.5424 & 0.005760 \\
$\mathrm{C}(\mathrm{Q})$ & 0.751 & 1 & 0.751 & 2.9268 & 0.137968 \\
$\mathrm{~A} \times \mathrm{B}$ & 2.509 & 1 & 2.509 & 9.7749 & 0.020416 \\
$\mathrm{~A} \times \mathrm{C}$ & 0.087 & 1 & 0.087 & 0.3382 & 0.582021 \\
$\mathrm{~B} \times \mathrm{C}$ & 0.109 & 1 & 0.109 & 0.4228 & 0.539613 \\
Error & 1.54 & 6 & 0.257 & & 0.1 \\
Lack of Fit & 1.542 & 5 & 0.30830 & 57.28 & \\
\hline
\end{tabular}

a) $R^{2}($ predict $)=97.43 \% ; R^{2}($ adjust $)=93.6 \% ; \alpha($ significance level $)=5 \%$.

boundary, each response surface plot had a clear peak and the corresponding contour plot had a clear highest point, which meant that the maximum butanol production could be achieved inside the design boundary. The butanol production rate increased with increasing temperature, $\mathrm{CaCO}_{3}$ concentrations and reaction time to the optimal levels, and then decreased with a further increase. Figure 1 represented the interaction between reaction time and temperature. Lower and higher levels of both the time and temperature did not result in higher butanol production. The shape of the response surface curves showed a moderate interaction between these tested variables. The response surface curve for the interaction of $\mathrm{CaCO}_{3}$ concentrations and temperature was represented in Figure 2. The shape of the contour showed a positive interaction between the two variables. The butanol production was found to increase with simultaneous increase in both the factors. This may be due to the buffering effect of $\mathrm{CaCO}_{3}$ on higher butanol production at optimum temperature. Figure 3 depicted the interaction of $\mathrm{CaCO}_{3}$ concentration and reaction time where the shape of the response surface also indicated a moderate interaction between these two factors. Extended period of reaction time might not lead to higher butanol production. In accordance with the previous data, the $P$ values of the interactive effect between temperature and reaction time, $\mathrm{CaCO}_{3}$ concentrations and reaction time on butanol production were not significant $(P>0.05)$, also indicating that these terms had little impact on butanol production and the $p$ value of the interactive effect between temperature and $\mathrm{CaCO}_{3}$ concentrations $(P<0.05)$ indicated that this term had a positive impact on butanol production. Thus the statistical methods were further verified in favor of the forecast and analysis of fermentation.

\subsection{Validation of the models}

Validation was carried out under conditions predicted by the model as follows: temperature $35^{\circ} \mathrm{C}$, the $\mathrm{CaCO}_{3}$ concentrations $5.043 \mathrm{~g} / \mathrm{L}$ and the reaction time $70 \mathrm{~h}$. Under the above

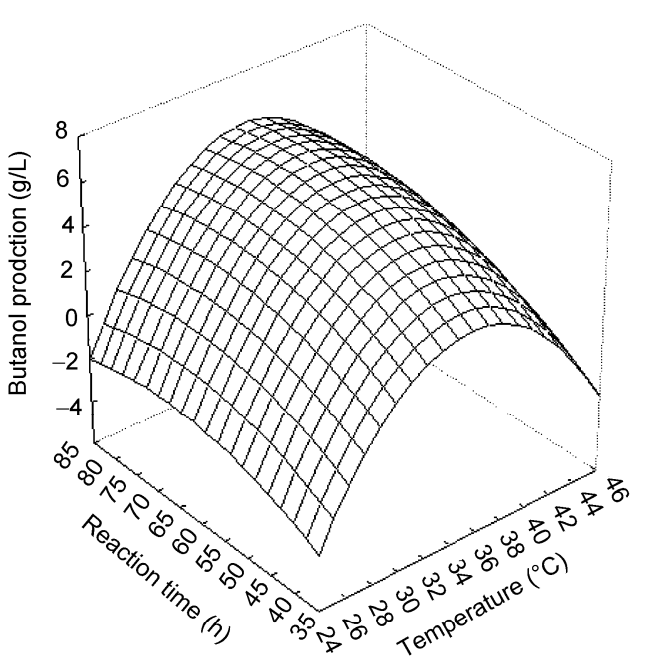

(a)

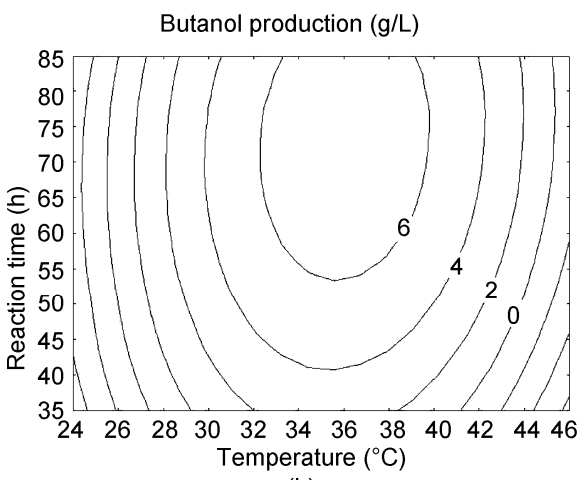

(b)

Figure 1 The response surface plot (a) and the corresponding contour plot (b) showing the effects of temperature and time on butanol production by $C$. acetobutylicum, with the $\mathrm{CaCO}_{3}$ level of $3.36 \mathrm{~g} / \mathrm{L}$.

optimized condition, the maximum production of butanol based on enzymatic hydrolysis was estimated as $6.57 \mathrm{~g} / \mathrm{L}$. The results were further verified by triplicate experiments and the maximum butanol yield was $6.20 \mathrm{~g} / \mathrm{L}$ (Figure 4). This suggests that the experimental value obtained was in 


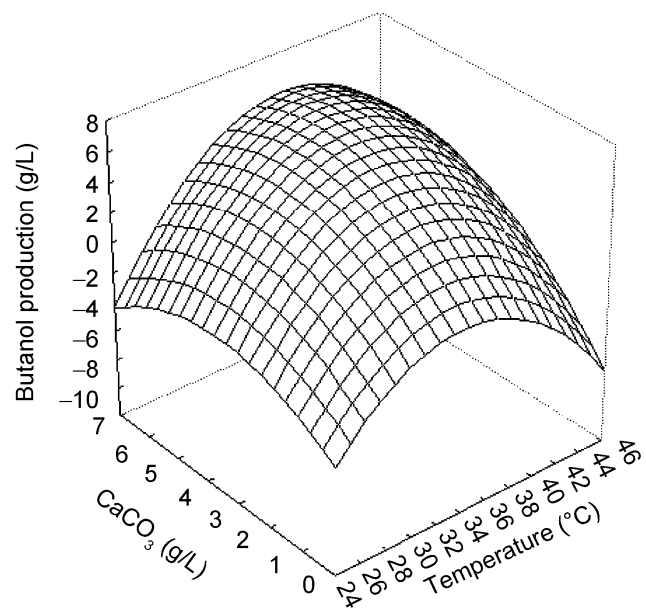

(a)

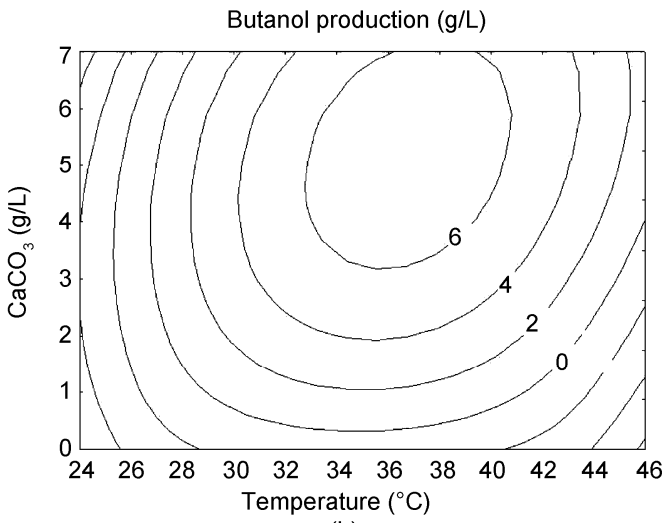

(b)

Figure 2 The response surface plot (a) and the corresponding contour plot (b) showing the effects of $\mathrm{CaCO}_{3}$ and temperature on butanol production by $C$. acetobutylicum, with the time level of $60 \mathrm{~h}$.

good agreement with the value calculated from the model.

The RSM designs used in the present investigation have been successfully applied in many recent biotechnological researches. However, to the best of our knowledge, no single report was obtained on butanol production optimization using corn straw hydrolysate by RSM design. In our study, the conversion rate of butanol production was $6.21 \mathrm{~g} / 100 \mathrm{~g}$ (corn straw). Successful bioconversion of these wastes would not only convert these waste substrates to useful chemicals such as butanol, thus economizing the process of biofuel production, but also solve waste disposal problems facing by the agricultural residues

\section{Conclusions}

P-B design and Central Composite Design were adopted to screen the key factors and identify optimal culture conditions which enhanced butanol production by $C$. acetobutylicum CICC8008. The results show that this statistical method offers an efficient and feasible approach for the

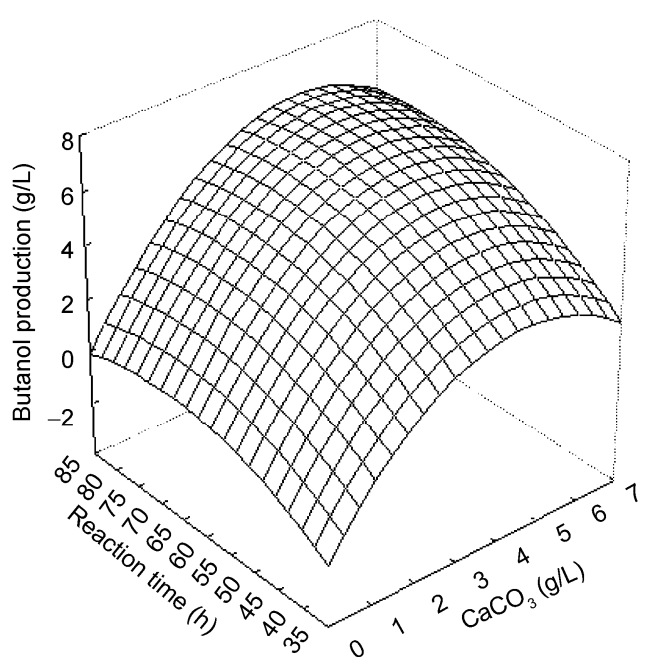

(a)

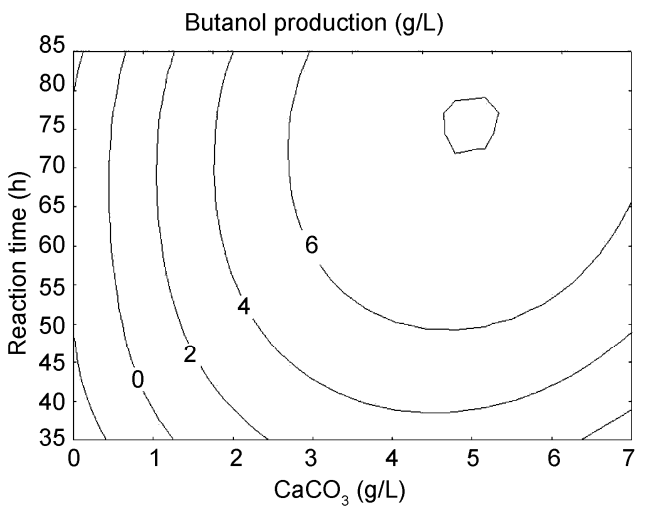

(b)

Figure 3 The response surface plot (a) and the corresponding contour plot (b) showing the effects of $\mathrm{CaCO}_{3}$ and time on butanol production by $C$. acetobutylicum, with the temperature level of $35^{\circ} \mathrm{C}$.

medium optimization for butanol production. The following conclusions could be drawn.

(1) $\mathrm{CaCO}_{3}$ had a very significant influence on butanol production from enzymatic hydrolysate of corn straw. Temperatures, $\mathrm{CaCO}_{3}$ concentrations and reaction time had

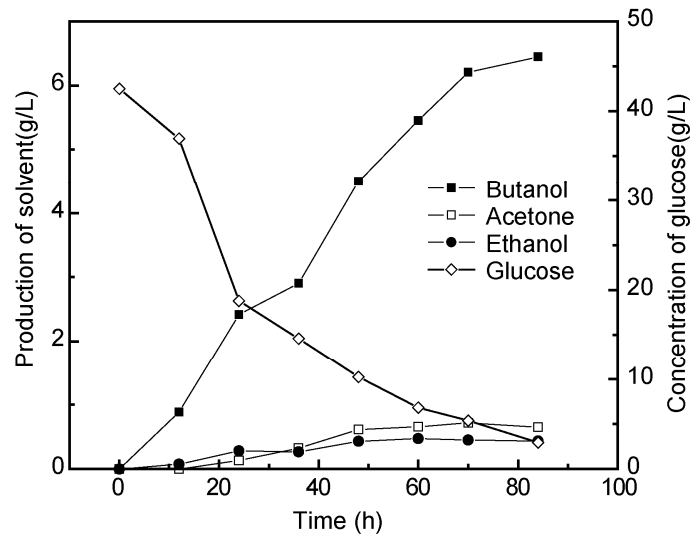

Figure 4 Butanol fermentation of enzymatic hydrolysate. 
some impact on fermentative butanol production individually and interactively.

(2) The optimal conditions of butanol fermentation from enzymatic hydrolysate of corn straw were as follows: 5.043 $\mathrm{g} / \mathrm{L}$ of $\mathrm{CaCO}_{3}, 70 \mathrm{~h}$ of fermentation period at $35^{\circ} \mathrm{C}$.

(3) The predicted and experimental butanol yields were found to be $6.57 \mathrm{~g} / \mathrm{L}$ and $6.20 \mathrm{~g} / \mathrm{L}$, respectively. In addition, the use of cheap agricultural residues as raw material for fermentative butanol is in favor of the great reduction in the cost of production medium.

1 Ezeji T C, Qureshi N, Karcher P, et al. Production of butanol from corn. In: Minteer S, ed. Alcoholic Fuels. Boca Raton: CRC Press, 2006

2 Formanek J, Mackie R, Blaschek H P. Enhanced butanol production by Clostridium beijerinckii BA101 grown in semidefined P2 medium containing 6 percent maltodextrin or glucose. Appl Environ Microbiol, 1997, 63: 2306-2310

3 Parekh M, Formanek J, Blaschek H P. Development of a cost-effective glucose-corn steep medium for the production of butanol by Clostridium beijerinckii. J Ind Microbiol Biotechnol, 1998, 21: 187-191

4 Parekh M, Formanek J, Blaschek H P. Pilot-scale production of butanol by Clostridium beijerinckii BA101 using low-cost fermentation medium based on corn steep water. Appl Microbiol Biotechnol, 1999, 51: $152-157$

5 Ladisch M R. Fermentation derived butanol and scenarios for its uses in energy-related applications. Enzyme Microbial Technol, 1991, 13: 280-283

6 Qureshi N, Maddox I S. Application of novel technology to the ABE fermentation process: An economic analysis. Appl Biochem Biotechnol, 1992, 34: 441-448

7 Qureshi N, Blaschek H P. Evaluation of recent advances in butanol fermentation, upstream, and downstream processing. Bioproc Biosys Eng, 2001, 24: 219-226

8 Jones D T, Woods D R. Acetone-butanol fermentation revisited. Microbiol Rev, 1986, 50: 484-524

9 Ezeji T C, Qureshi N, Blaschek H P. Bioproduction of butanol from biomass: From genes to bioreactors. Curr Opin Biotechnol, 2007, 18: 220-227

10 Ezeji, T C, Qureshi N, Blaschek H P. Butanol production from agricultural residues: Impact of degradation products on Clostridium beijerinckii growth and butanol fermentation. Biotechnol Bioeng, 2007, 97: $1460-1469$
11 Tabka M G, Herpoël-Gimbert I, Monod F, et al. Enzymatic saccharification of wheat straw for bioethanolproduction by a combined cellulose xylanase and feruloyl esterase treatment. Enzyme Microb Technol, 2006, 39: 897-902

12 Esteghlalian A, Hashimoto A G, Fenske J J, et al. Modeling and optimization of the dilute-sulfuric-acid pretreatment of corn stover, poplar and switchgrass. Bioresour Technol, 1997, 59: 129-136

13 Qureshi N, Saha B, Cotta M. Butanol production from wheat straw hydrolysate using Clostridium Beijerinckii. Bioproc Biosys Eng, 2007, 30: 419-427

14 Madihah M S, Ariff A B, Sahaid K M, et al. Direct fermentation of gelatinized sago starch to acetone-butanol-ethanol by Clostridium acetobutylicum. World J Microbiol Biotechnol, 2001, 17: 567-576

15 Lai M C, Traxler R W. A coupled two-stage continuous fermentation for solvent production by Clostridium acetobutylicum. Enzyme Microb Technol, 1994, 16: 1021-1025

16 Guo W Q, Ren N Q, Wang W S, et al. Optimization of culture conditions for hydrogen production by Ethanoligenens harbinense B49 using response surface methodology. Bioresour Technol, 2009, 100: 1193-1196

17 Chung K T, Bryant M P, Robert E. Hungate: Pioneer of anaerobic microbial ecology. Anaerobe, 1997, 3: 213-217

18 Yukihiro T, Katsuhisa T, Genta K, et al. High butanol production by Clostridium saccharoperbutylacetonicum N1-4 in fed-batch culture with $\mathrm{pH}$-Stat continuous butyric acid and glucose feeding method. J Biosci Bioeng, 2004, 98: 263-269

19 Wang Q H, Wang X Q, Ma H Z. Glucoamylase production from food waste by Aspergillus niger under submerged fermentation. Process Biochem, 2008, 43: 280-286

20 Gupta N, Sahai V, Gupta R. Alkaline lipase from a novel strain Burkholderia multivorans: Statistical medium optimization and production in a bioreactor. Process Biochem, 2007, 42: 518-526

21 Wang J L, Wei W. Optimization of fermentative hydrogen production process using genetic algorithm based on neural network and response surface methodology. Int J Hydrogen Energy, 2008, 34: 255-261

22 Gangadharan D, Sivaramakrishnan S, Nampoothiri K M, et al. Response surface methodology for the optimization of alpha amylase production by Bacillus amyloliquefaciens. Bioresour Technol, 2008, 99: 4597-4602

23 Eevera T, Rajendran K, Saradha S. Biodiesel production process optimization and characterization to assess the suitability of the product for varied environmental conditions. Renewable Energy, 2008, 34: $762-765$

24 Loukas Y L. A Plackett-Burnam screening design directs the efficient formulation of multicomponent DRV liposomes. J Pharm Biomed Anal, 2001, 26: 255-263

Open Access This article is distributed under the terms of the Creative Commons Attribution License which permits any use, distribution, and reproduction in any medium, provided the original author(s) and source are credited. 